\title{
Rheumatoid Nodule Causing Perforation of Anterior Mitral Leaflet and Severe Mitral Regurgitation: A Rare Case Report
}

\author{
Jayanth Koneru1 ${ }^{*}$, Matthew Cholankeril2, Priyank Shah'1, Fayez Shamoon ${ }^{3}$, Hartaj Virk1, \\ Mahesh Bikkina1 \\ ${ }^{1}$ Seton Hall Cardiology Fellowship Program, St. Joseph's Regional Medical Center, Paterson, USA \\ ${ }^{2}$ Seton Hall Internal Medicine Program, St. Michael's Medical Center, Newark, USA \\ ${ }^{3}$ Seton Hall Cardiology Fellowship Program, St. Michael's Medical Center, Newark, USA \\ Email: "koneru.jayanth@gmail.com, matthew.cholankeril@gmail.com, priyank 221084@yahoo.com, \\ fshamoon03@gmail.com, hartaj.virk@hotmail.com, mbikkina@gmail.com
}

Received 2 March 2014; revised 5 April 2014; accepted 14 April 2014

Copyright (C) 2014 by authors and Scientific Research Publishing Inc.

This work is licensed under the Creative Commons Attribution International License (CC BY).

http://creativecommons.org/licenses/by/4.0/

(c) (i) Open Access

\begin{abstract}
Rheumatoid arthritis (RA) is a systemic disorder that is chronic in nature and difficult to treat. RA presents in many variants. Here we present an interesting case only seldom described before. Our patient presented to emergency room with acute shortness of breath and was seen to have acute pulmonary edema. Patient later had urgent echocardiography which revealed severe mitral regurgitation from ruptured anterior leaflet. Patient was taken for heart valve replacement and was found to have RA nodule on ruptured leaflet. There are cases involving aortic valve but to our knowledge there are no reports of RA nodule on mitral leaflet.
\end{abstract}

Keywords

Rheumatoid Arthritis, Rheumatoid Nodule, Heart Failure, Mitral Valve Replacement

\section{Introduction}

Rheumatoid arthritis is a chronic, systemic inflammatory autoimmune disorder that affects several tissues and organs, principally affecting synovial joints. Rheumatoid arthritis can produce diffuse inflammation of the serous membranes and nodular lesions can commonly be seen in subcutaneous tissue. Rheumatoid nodule presents as a local swelling or tissue lump, which occurs almost exclusively in association with rheumatoid arthritis.

${ }^{*}$ Corresponding author.

How to cite this paper: Koneru, J., et al. (2014) Rheumatoid Nodule Causing Perforation of Anterior Mitral Leaflet and Severe Mitral Regurgitation: A Rare Case Report. World Journal of Cardiovascular Diseases, 4, 156-159.

http://dx.doi.org/10.4236/wjcd.2014.44023 
About $5 \%$ of rheumatoid arthritis patients have such nodules within 2 years of disease onset, and the cumulative prevalence is about $25 \%$. Nodules are seen in the heart and rarely do they produce symptoms or need surgical intervention.

\section{Case Report}

H.A. is a 38 years old African American woman with past medical history significant for longstanding rheumatoid arthritis, psoriasis, and necrotizing fasciitis who presented to the emergency room with sudden onset of shortness of breath and dry cough. On examination, she was tachycardic with a heart rate of 111 and had a blood pressure of 123/98 as well as had a distended jugular venous pulse. She had an IV/VI holosystolic murmur that radiated to the back in addition to bibasilar rales. The patient was clearly in florid heart failure with pulmonary edema and was subsequently admitted to the coronary care unit. She was diuresed, given IV steroids as well as antibiotics, as it was unclear at this time whether her chest X-ray showed a superimposed pneumonia in the context of the pleural effusion. A bedside echocardiogram revealed severe mitral regurgitation with prolapse of the anterior leaflet and possible chordae rupture (Figure 1(a) and Figure 1(b)). She was urgently referred for surgery where she underwent mitral valve replacement with a 25/33 mm On-X valve. Intraoperative inspection of

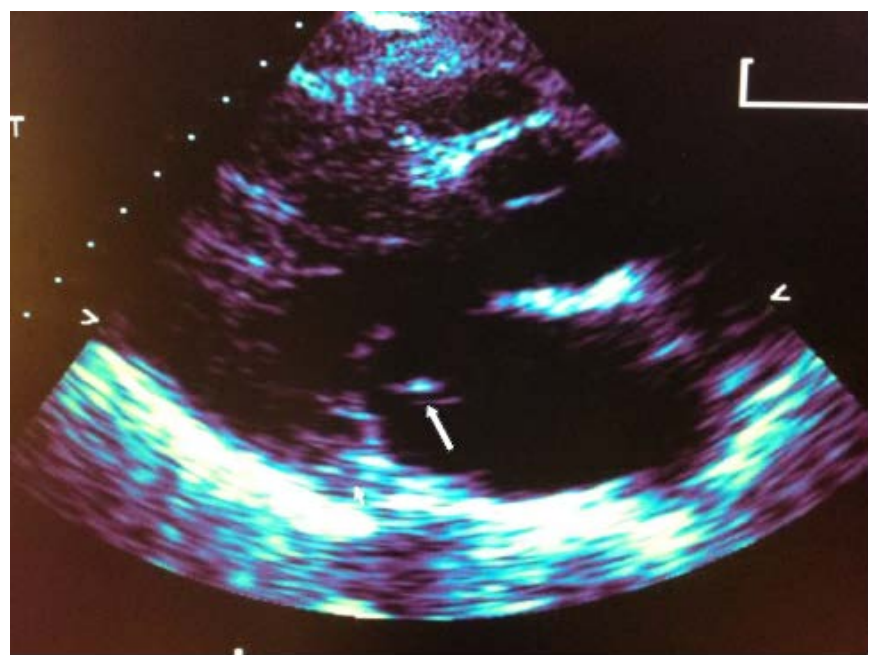

(a)

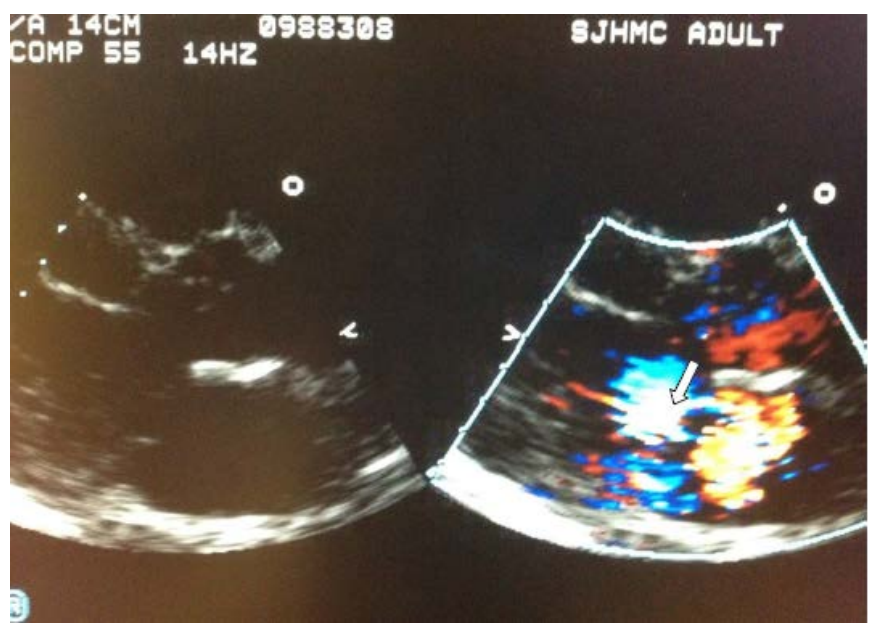

(b)

Figure 1. (a) Echocardiogram revealed prolapse of the anterior leaflet and possible chordae rupture. (b) Echocardiogram revealed severe mitral regurgitation with prolapse of the anterior leaflet and possible chordae rupture. 
the valve demonstrated a severely inflamed rheumatic mitral valve with the appearance of an acute versus chronic or subclinical bacterial endocarditis. The specimen was sent for microbiological as well as pathological examination. The final pathology of the specimen was consistent with a rheumatoid nodule with superimposed acute and chronic inflammation and was negative for microorganisms. The patient did well postoperatively and was started on anticoagulation with coumadin on postoperative day one. She was transferred to the floor, tolerated soft mechanical diet, and was ambulating by the fourth day. She was discharged home several days later on medical therapy including coumadin, amiodarone, lasix, enalapril, lopressor, and prednisone, to follow up with her primary care physician, rheumatologist, and cardiothoracic surgeon within one week.

\section{Discussion}

Patients with rheumatoid arthritis often have cardiac involvement complicating their disease course. Many of these complications are found during autopsy since only about $3 \%$ of patients are with rheumatoid arthritis exhibit manifestations of cardiac signs and symptoms. The majority of cardiac complications is non-specific and is secondary to pericarditis, myocarditis, arteritis, chronic endocarditis, and valvular fibrosis, while specific findings of rheumatoid granulomata and involvement of valvular structures are quite rare [1]. A review of the literature demonstrates that nodules are generally found in two main locations, within the myocardium or in the valve or valve ring [2]. Intramyocardial rheumatoid nodules rarely affect cardiac function. However extensive replacement of the muscle by nodules can cause congestive heart failure and infected nodules can lead to abscess formation and perforation [3] [4]. Intracardiac rheumatoid nodules have a characteristic appearance and are morphologically similar to rheumatoid subcutaneous tissue nodules. The histological findings include a central zone of necrotic connective tissue surrounded by histiocytes, fibroblasts, and multinucleated giant cells. The outer layer of the inflammatory infiltrate consists of lymphocytes, histiocytes, plasma cells, and polymorphonuclear neutrophils [5] [6].

Nodules have been reported to mimic atrial myxomas or cause conduction abnormalities in the sinoatrial node, atrioventricular node, and His-Purkinje system by compression, direct invasion of the conduction tissues, or by impairing the tissue's blood supply [7]. Cases of left bundle branch block and complete heart block have been reported in patient with intramyocardial nodules. With direct valve involvement, rheumatoid nodules usually begin as a local area of necrosis in the central portion of the valve cusp or in the annulus, with a surrounding rim of fibrous tissue. Generally, small nodules do no disrupt valvular function, but extensive nodule involvement can obstruct the mobility of the valve, leading to valvular deformity and incompetence [8]. Although all four major valves can be affected by rheumatoid nodules, mitral valve involvement occurs more frequently than aortic or tricuspid [9]. The literature suggests that aortic regurgitation may be more likely to produce functional impairment than mitral regurgitation [10], and some cases of AR progress to abrupt decompensation requiring emergency valve replacement [11] [12].

\section{References}

[1] Turiel, M., Sitia, S. and Atzeni, F. (2010) The Heart in Rheumatoid Arthritis. Autoimmunity Reviews, 9, 414-418. http://dx.doi.org/10.1016/j.autrev.2009.11.002

[2] Roldan, C., DeLong, C. and Qualls, C. (2007) Characterization of Valvular Heart Disease in Rheumatoid Arthritis by Transesophageal Echocardiography and Clinical Correlates. The American Journal of Cardiology, 100, 496-502.

[3] Arakawa, K., Yamazawa, M. and Morita, Y. (2005) Giant Rheumatoid Nodule Causing Simultaneous Atrio Ventricular and Severe Mitral Regurgitation: A Case Report. Journal of Cardiology, 46, 77-83.

[4] Giladi, H., Sukenik, S. and Flusser, D. (2004) A Rare Case of Enterobacter Endocarditis Superimposed on a Mitral Valve Rheumatoid Nodule. Journal of Clinical Rheumatology, 31, 1001-1003.

[5] Longo, M. and Remetz, M. (1998) Cardiovascular Manifestations of Systemic Autoimmune Diseases. Clinics in Chest Medicine, 19, 793-807. http://dx.doi.org/10.1016/S0272-5231(05)70117-9

[6] Ojeda, V.J., Stuckey, B.G. and Owca, E.T. (1986) Cardiac Rheumatoid Nodules. Medical Journal of Australia, 144, 92-93.

[7] Guedes, C., Bianchi, F.P. and Cormier, B. (2001) Cardiac Manifestations of Rheumatoid Arthritis: A Case Control Transesophageal Echocardiography Study in 30 Patients. Arthritis Care \& Research, 45, 129-135. http://dx.doi.org/10.1002/1529-0131(200104)45:2<129::AID-ANR164>3.0.CO;2-K

[8] Chand, E.M., Freant, L.J. and Rubin, J.W. (1999) Aortic Valve Rheumatoid Nodules Producing Clinical Aortic Regur- 
gitation and a Review of the Literature. Cardiovascular Pathology, 8, 333-338. http://dx.doi.org/10.1016/S1054-8807(99)00024-1

[9] Mounct, F.S., Soula, P. and Concina, P. (1997) A Rare Case of Embolizing Cardiac Tumor: Rheumatoid Nodule of the Mitral Valve. Journal of Heart Valve Disease, 6, 77-78.

[10] Didry, C., Combe, B. and Flaisler, F. (1992) Rheumatoid Aortic Insufficiencies: Severity of the Prognosis. Rev Rhum Mal Osteoartic, 59, 571-576.

[11] Levine, A.J., Dimitri, W.R. and Bonser, R.S. (1999) Aortic Regurgitation in Rheumatoid Arthritis Necessitating Aortic Valve Replacement. European Journal of Cardiothoracic Surgery, 15, 213-214. http://dx.doi.org/10.1016/S1010-7940(98)00294-2

[12] Iveson, J.M., Thadani, U. and Ionescu, M. (1975) Aortic Valve Incompetence and Replacement in Rheumatoid Arthritis. Annals of Rheumatic Disease, 34, 312-320. http://dx.doi.org/10.1136/ard.34.4.312 